Early release, published at www.cmaj.ca on December 21, 2009. Subject to revision.

BOOKS

\section{Trials and tribulations}

\author{
When Experiments Travel: Clinical Trials \\ and the Global Search for Human \\ Subjects \\ Adriana Petryna \\ Princeton University Press; 2009. \\ $258 \mathrm{pp} \$ 24.99$
}

$\mathrm{I}$ n June, the drug company Genzyme shut down production of Cerezyme (imiglucerase injection) - a lifesaving medication for those with Gaucher disease - after a manufacturing plant near Boston, Massachusetts was contaminated by a virus. With supplies of the drug falling sharply, the company advised the 5000 people worldwide who take Cerezyme to temporarily skip or reduce doses. Despite cutting back on their medications, patients have done well. It's a conundrum that's understandable after reading this book.

In researching this book, anthropologist Adriana Petryna spent time in Brazil getting to know the family of Pedro Souza. Pedro's parents discovered in 1994 that his anemia and other health problems were due to Gaucher disease; then they learned they couldn't afford Cerezyme's US $\$ 200000$ annual price tag. They sued the government to obtain access to the drug and won. This was a wonderful outcome for Pedro, but it meant Brazil was on the hook for the \$100-million annual cost of treating all Brazilians with the disease.

We then meet the man who tried to solve this problem, Paulo Picon of Brazil's Fundação Oswaldo Cruz, whose team produced national guidelines, called Protocolo, for Brazilians' use of "exceptional" drugs. Since the dose of Cerezyme recommended in the package insert was not established in a clinical trial as a minimum effective dose and Gaucher experts in the US and Israel had reported good outcomes using doses as low as one-eighth of the company's recommendation, Picon's Cerezyme guide-

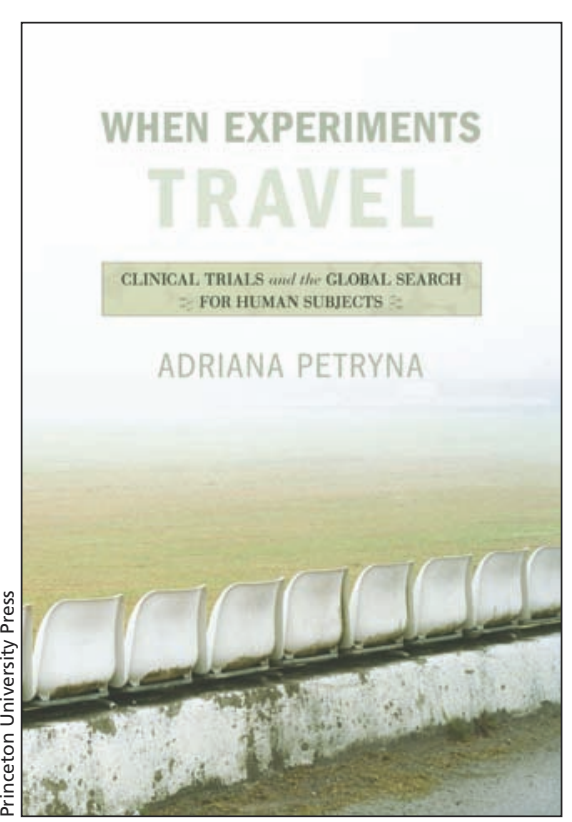

line called for patients to start on a fraction of the recommended dose. This could ensure considerable savings for the government. But soon after the guideline was published, Petryna writes, "pressure came from all sides to abandon" it. Brazilian doctors claimed that following the guideline could harm patients and a Brazilian advocacy group for Gaucher patients noted in its newsletter that "dosages should be defined by specialists, not by a protocol." Today, with the dose lowered because of the shortage, the guideline Picon prepared seems sensible.

This narrative, which takes readers behind the scenes to illuminate the most contentious areas of debate over drug research and marketing, is a highlight of this book. Venturing widely in Brazil, Eastern Europe and the US and providing complete confidentiality to numerous sources referred to by pseudonyms, Petryna manages to expose little known areas of the clinical trials industry, including the notion of "salvage" or "rescue" research, where projects "that lost commercial interest" in more developed nations are "dumped" on clinical trial leaders in Eastern Europe or Latin America.

For example, an ineffective antidepressant that never received US Food and Drug Administration approval was later tested and marketed in Brazil for "mild depression." But as Petryna discovers, the doctor who led that effort now questions the ethics of the research. Mild depression is a "made-up" illness, the doctor tells Petryna, and she describes the system she was part of as "a money machine." Through such interviews, this book offers revealing insights into the role that the clinical trials industry plays in the use of medication worldwide.

However, lines of academic gobbledygook are littered throughout When Experiments Travel, making the text less than readable at times. To give just a few examples, the author's sources are called "interlocutors;" her subject is "global experimentality;" local doctors, families and patients in Brazil are "agentive forces in a rapidly growing drug market" and their struggles show that "neoliberal medical globalization transfers human rights and justice concerns away from traditional public domains to the privatized body of the atomized citizen."

Readers must also endure introductions to texts in anthropology, sociology and economics through short treatises that appear to have been written for graduate students.

In a recent Lancet article, Petryna with Picon and others, clearly and succinctly reviewed the debate in Brazil over courtordered access to high-cost drugs. ${ }^{1}$ It was good to see these findings brought forward in a journal since the academic language of the book may drive readers away and its disclosures are too important to be buried in a course syllabus.

\section{Miriam Shuchman MD \\ Chair \\ Research Ethics Board \\ Women's College Hospital \\ Toronto, Ont.}

\section{REFERENCE}

1. Biehl J, Petryna A, Gertner A, et al. Judicialization of the right to health in Brazil. Lancet 2009;373:2182-4.

Dr. Shuchman won the 2005 Shaughnessy Cohen Prize honouring political writing excellence for her book The Drug Trial. 